\title{
Jaringan Sensor Nirkabel: Studi dan Evaluasi Kinerja LoRa Transmitter dan Long Range Radio Frekuensi (RF) Pada Luar Ruang
}

\author{
Rifki Muhendra ${ }^{* 1}$, Naufal Ismail Kreshnaviyanto ${ }^{2}$, Aisyah Amin ${ }^{3}$ \\ ${ }^{1}$ Teknik Industri, Fakultas Teknik, UBJ, Jakarta, Indonesia \\ ${ }^{2}$ Fisika, Fakultas Matematika dan Ilmu Pengetahuan Alam, ITB, Bandung, Indonesia \\ ${ }^{3}$ Fisika, Universitas Halim Sanusi, Bandung, Indonesia \\ e-mail: *rifki.muhendra@dsn.ubharajaya.ac.id, ${ }^{2}$ naufalismailk@gmail.com, \\ 3aisyahmuhendra55@gmail.com
}

\begin{abstract}
Transmitters are the backbone of communication on wireless sensor networks. Most transmitters use ism band frequencies so the communication range is limited to $100 \mathrm{~m}$. Some types of transmitters that have longdistance communication capabilities are nRF 24 $1 \mathrm{~km}$ and LoRa. The paper reports a comparative study between nRF24 $1 \mathrm{~km}$ and LoRa in data communication, power consumption and resistance to obstacles. The results showed that LoRa has a range capability of $1.6 \mathrm{~km}$ and nRF24 has a delivery capability of $1 \mathrm{~km}$. The $1 \mathrm{~km} \mathrm{NRF24}$ is more suitable for long-distance communication that requires high speed and is also resistant to non-line of sight obstacles.
\end{abstract}

Keywords : Transmitter, Wireless Sensor Network, nRF24 1 km, LoRa

\section{PENDAHULUAN}

Transmitter pada jaringan sensor nirkabel (JSN) berfungsi untuk berkomunikasi dari satu node ke node yang lain atau node dengan sebuah jaringan. Transmitter yang baik biasanya memiliki kemampuan dalam mengirimkan pesan dengan baik, tahan terhadap gangguan komunikasi dan berdaya rendah. Selain itu, kemudahan dihubungkan dengan perangkat lain dan cakupan komunikasi yang bisa dicapai menjadi aspek penting dalam pemilihan transmitter dalam sistem JSN.

Beberapa teknologi transmitter yang digunakan dalam beberapa penelitian sebelumnya antara lain zigbee (Kaleem, et al., 2016);(Mohassel, et al., 2014) RF (Muhendra, et al., 2016) dan wifi (Shailandra, 2012); (Li, et al., 2011); (Muhendra \& Arzi, 2017). Transmitter-transmitter ini menggunakan frekuensi ism band yaitu $433 \mathrm{MHz}, 915 \mathrm{MHz}$ dan yang paling umum adalah 2,4 ghz(Vullers et al., 2010). Karna bersifat non license, transmitter-transmitter ini memiliki keterbatasan jangkauan pengiriman yaitu tidak lebih dari $100 \mathrm{~m}$. Untuk kebutuhan pengiriman data lebih dari $100 \mathrm{~m}$, para peneliti biasanya merekayasa transmitter-transmitter ini dengan meningkatkan kemampuan antenna transmitter dan menambahkan penguat daya dalam rangkaian transmitter. Hasilnya transmitter jenis rf dapat meningkatkan jangkauannya hingga $1 \mathrm{~km}$ atau lebih.

LoRa merupakan teknologi transmitter yang memiliki jangkauan komunikasi jarak jauh. Berbeda dari transmitter rf jarak jauh sebelumnya, LoRa datang dengan format modulasi yang unik yang biasa dikenal dengan chirp spread(Petäjäjärvi et al., 2017). Pada chirp spread, data yang ditransmisikan berupa simbol akan diwakili oleh sinyal kicauan dengan rentang frekuensi. Dalam modulasi LoRa, simbol dapat dikonfigurasi dengan mengubah parameter spreading factor (sf) dan bandwidth. Semakin besar nilai sf dan bandwidth yang digunakan, jangkauan pengiriman data pada LoRa akan semakin jauh (Augustin, et al., 2016); (Bor, et al., 2016); (Wixted, et al., 2016)

Pada penelitian ini dilakukan studi dan evaluasi kinerja teknologi LoRa dan rf jarak jauh pada pengiriman data dalam jaringan. Penelitian ini dilakukan luar ruangan dan tanpa rekayasa untuk membentuk kondisi idel dalam pengiriman. Tujuannya adalah mengetahui kemampuan transmitter secara actual sebelum diaplikasi untuk beberapa sistem pemantauan dan kontrol berbasis JSN. Dengan hasil penelitian ini diharapkan penelitan selanjutnya tidak disibukkan lagi dengan kondisi perangkat 
dan memudahkan dalam pengaplikasian pada sistem penelitian selanjutnya.

\section{METODE PENELITIAN}

Transmitter yang digunakan pada penelitian ini adalah nRF24 $1 \mathrm{~km}$ dan LoRa ra 02. Beberapa penjelasan mengenai ke dua transmitter ini antara lain:

\section{$n R F 241 \mathrm{~km}$}

Modul transmitter keluaran nordic ini beroperasi pada frekuensi 2,4 Ghz dengan data rate yang dapat diatur sebesar $250 \mathrm{kbps}, 1 \mathrm{mbps}$ and 2mbps. NRF24 $1 \mathrm{~km}$ memiliki $125 \mathrm{kanal}$ transmisi yang dapat diatur pengunaannya untuk menghindari kanal yang dalam keadaan sibuk. NRF24 $1 \mathrm{~km}$ bekerja pada tegangan 3,3 vdc dengan arus pada saat pengiriman data sebesar 115 ma dan penerimaan sebesar 45 ma. Bentuk fisik dari nRF24 $1 \mathrm{~km}$ dapat dilihat pada gambar 1.

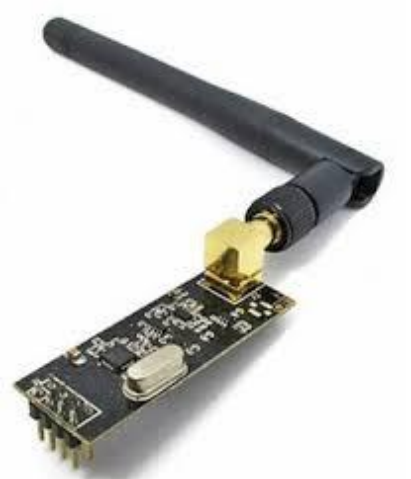

Gambar 1 Bentuk fisik nRF24 $1 \mathrm{~km}$

\section{LoRa ra 02}

Modul transmitter keluaran semtech ini beroperasi pada frekuensi $433 \mathrm{MHz}$ dengan data rate yang dapat diatur sebesar $300 \mathrm{kbps}$ dan sf mulai dari 6 sampai dengan 12. LoRa ra 02 bekerja pada tegangan 3,3 vdc dengan arus pada saat pengiriman data sebesar 120 ma dan penerimaan sebesar 12 ma. Bentuk fisik dari LoRa ra 02 dapat dilihat pada gambar 2.

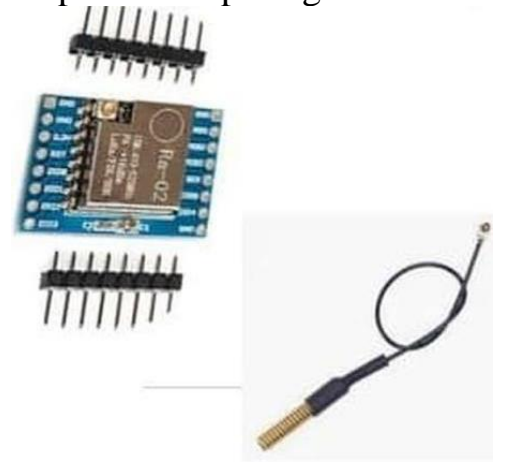

Gambar 2 Bentuk fisik LoRa ra 02

\section{Node JSN}

Copyright () 2021 Jurnal Jaring SainTek April 2021
Dalam penelitian ini dirancang beberapa buah node JSN menggunakan nRF24 $1 \mathrm{~km}$ dan LoRa ra 02 dengan skema umum seperti gambar 3.

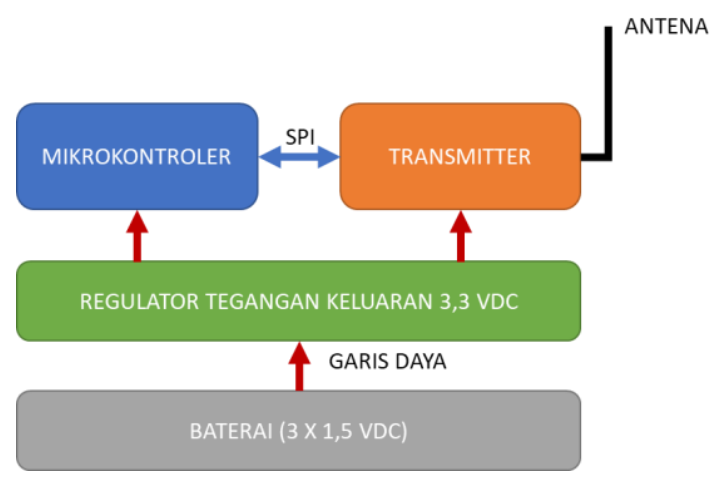

Gambar 3 Skema node JSN
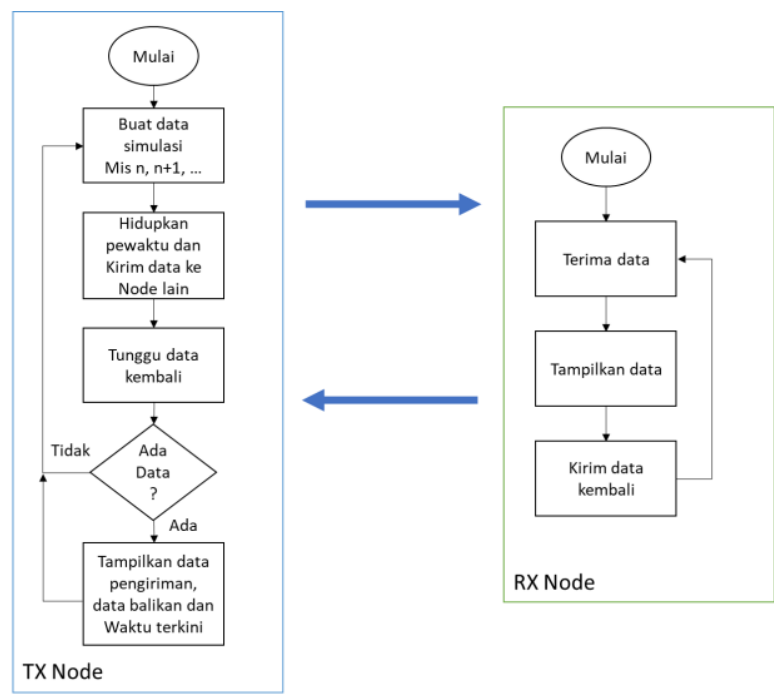

Gambar 4 Alur pemprograman node JSN, kiri : tx node dan kanan : rx node

Node JSN terdiri dari mikrokontroler, transmitter + antena, baterai dan regulator tegangan. Mikrokontroler yang digunakan adalah arduino promini. Arduino promini adalah jenis modul mikrokontroler keluarga arduino berukuran kecil dengan tegangan operasi 3,3 VDC. Mikrokontroler ini berfungsi sebagai pembangkit data simulasi dan pengatur komunikasi data keluar masuk. Mikrokontroler terhubung dengan transmitter menggunakan antarmuka serial peripheral interface (SPI). Mikrokontroler dan transmitter di catu oleh 3 buah baterai 1,5 vdc dengan tambahan regulator tegangan keluaran 3,3 vdc. Adapun jenis antenna yang digunakan adalah sesuai transmitter pada gambar 1 dan 2. Pemprograman digunakan software arduino ide 1.8.13. Alur pemprograman arduino dapat dilihat pada gambar 4 . 
Dalam pembuatan program dirancang untuk 2 node JSN yaitu tx node (pengirim data) dan rx node (tujuan). Untuk tx node dimulai dengan pembuatan data simulasi berupa bilangan angka (n), pewaktu diaktifkan dalam mili detik, dan prosedur kirim data dilakukan. Kemudian mikrokontroler menunggu data balikan. Jika ada data balikan, maka tampilkan data pengiriman, data balikan, dan waktu terkini, kemudian kembali buat data simulasi baru $(n+1)$ dan lakukan perulangan. Jika tidak ada data balikan, kembali buat data simulasi baru dan lakukan perulangan. Untuk rx node dimulai dengan menerima data, menampilkan data dan mengembalikan data yang diterima ke node pengirim (tx node). Kedua program ini dirancang khusus untuk mengukur \% keberhasilan pengiriman data dan kecepatan komunikasi. Program tx node dan rx node memang dibuat terus berulang tanpa henti. Ini bertujuan untuk terus berkomuniasi dan menfasilitasi pengukuran data, serta memungkinkan mendetaksi kesalahan jika terdapat ketidak sesuaian pada data komunikasi.

\section{Pengukuran Sistem}

Untuk mengetahui performansi pengiriman data untuk node JSN berbasis nRF24 $1 \mathrm{~km}$ dan LoRa ra 02 dilakukan beberapa pengukuran dilapangan terbuka. Beberapa pengukuran dijelaskan dibawah ini. 1. Jarak terhadap packet delivery rate (PDR)

Pengukuran ini dilakukan untuk mengetahui jarak maksimum pengukuran yang dapat dicapai masing-masing node JSN. Packet delivery rate adalah ukuran metode pengukuran keberhasilan pengiriman data dengan menghitung jumlah data kembali terhadap data yang dikirimkan node pengirim. Untuk lebih mudahnya, jumlah data yang dikirimkan dibatasi sebanyak 100 data pengiriman. 1 data yang berhasil kembali berarti bertambah $1 \%$ keberhasilan komunikasi. Jarak node dari gound (jalan) adalah $1,5 \mathrm{~m}$ dimana tx node dibuat diam dan rx node bergerak untuk mencapai titik maksimum. Adapun gambaran situasi pengukuran ini dapat dilihat pada gambar 5.

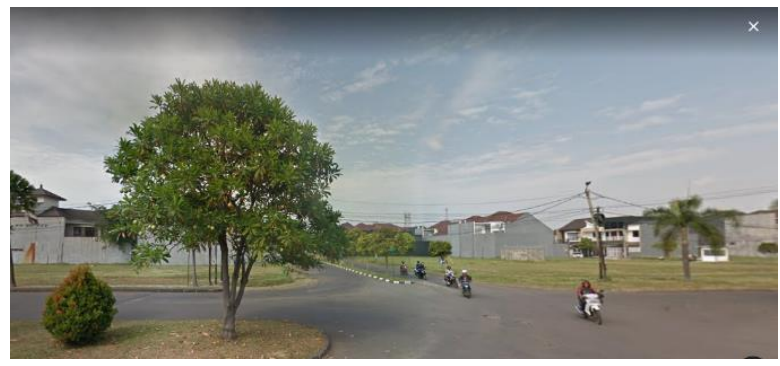

Gambar 5 Situasi pengukuran node JSN

Beberapa pengaturan pemprograman untuk masing-masing node yaitu node JSN nRF24 $1 \mathrm{~km}$ diatur dengan maksimal data rate 2 mbps dan node JSN LoRa ra 02 maksimum data rate $300 \mathrm{kbps}$ dengan pengaturan khusus pengambilan data yaitu sf 8 , sf 10 dan sf 12 . Grafik hasil pengukuran jarak terhadap \% pdr ditunjukkan gambar 6 .

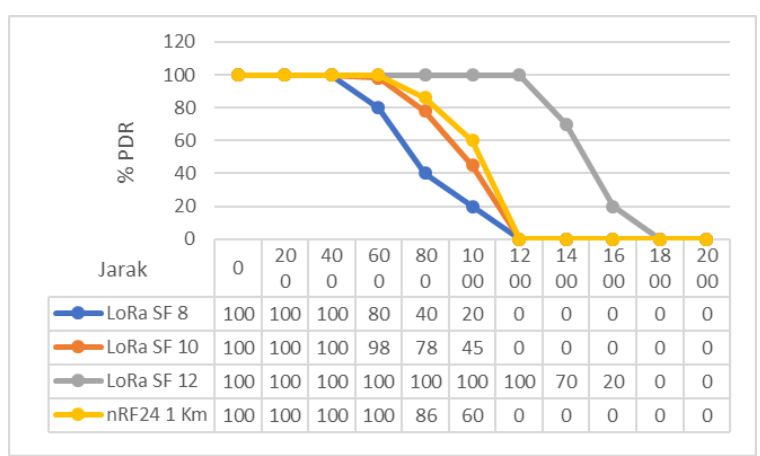

Gambar 6 Grafik pengukuran persentase pdr terhadap jarak

Berdasarkan gambar 6, jarak terjauh yang dapat dicapai node JSN LoRa adalah 1,6 km dengan setingan sf 12 . Sedangkan node JSN nrf $241 \mathrm{~km}$ sejauh $1 \mathrm{~km}$. Perbandingan persentase pdr node JSN LoRa sf 12 dan nRF24 $1 \mathrm{~km}$ pada titik $1 \mathrm{~km}$ adalah $100: 60$. Secara umum grafik ini menunjukkan bahwa LoRa memiliki kemampuan pengiriman data lebih jauh dibandingkan nRF24 $1 \mathrm{~km}$.

2. Konsumsi daya

Pada pengukuran ini dilakukan pada jarak pengiriman $100 \mathrm{~m}$. jarak ini diambil karena dari kedua transmitter ini yaitu LoRa dan NRF24 memiliki persentasi PDR sebesar 100 $\%$. Pengukuran ini berfungsi untuk mengetahui konsumsi daya actual yang dibutuhkan node JSN dalam mengirimkan paket data. Berdasarkan rumus daya yaitu $\mathrm{p}=\mathrm{v}$. I, dimana $\mathrm{v}$ adalah tegangan dan $\mathrm{i}$ adalah arus. Karena tegangan masing-masing node JSN adalah 3,3 $\mathrm{v}$, maka pengukuran konsumsi daya ini ddapat diwakili dengan mengukur arus masing-masing node JSN ketika mengirimkan data (mode tx). 
Pengukuran arus mode tx pada masing-masing node JSN dapat dilihat pada gambar 7.

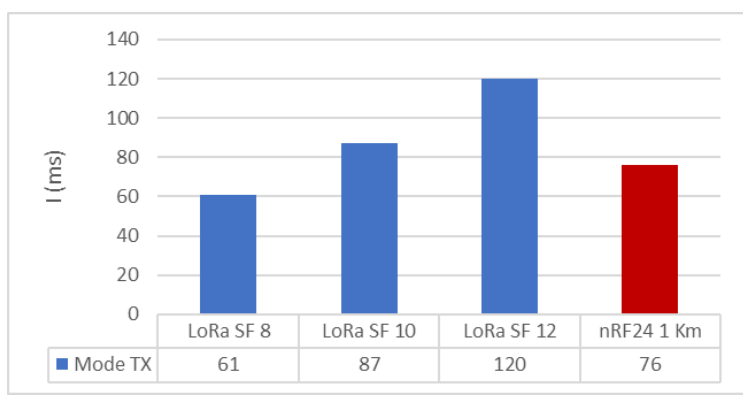

Gambar 7 Grafik pengukuran konsumsi daya node JSN

Pengukuran arus pada mode tx masingmasing untuk node LoRa sf 8 , sf 10, sf 12 dan node JSN nrf $241 \mathrm{~km}$ adalah $61 \mathrm{ma}, 87 \mathrm{ma}, 120$ ma dan 76 ma. Node LoRa sf 8 memiliki konsumsi arus paling kecil dan sf 12 paling besar mengkonsumsi listrik. Sedangkan node JSN nRF24 $1 \mathrm{~km}$ berada diantara konsumsi arus LoRa sf 8 dan sf 10.

3. Kecepatan transmisi data

Pengukuran ini dilakukan untuk mengatahui kecepatan transmisi data untuk masing-masing node JSN. Seperti halnya pengukuran konsumsi daya, pengukuran transimsi data dilakukan pada jarak $100 \mathrm{~m}$ karena punya persentase PDR sebesar $100 \%$. Kecepatan yang diukur disini bukanlah kecepatan yang sebenarnya, melainkan kecepatan respon dari device transmitter dalam mengirimkan sebuah paket data. Berdasarkan rumus kecepatan gerak lurus yaitu $\mathrm{v}=\mathrm{s} / \mathrm{t}$, dimana $\mathrm{s}$ adalah jarak pengukuran dan $\mathrm{t}$ adalah waktu tempuh pengiriman data. Untuk mendapatkan nilai kecepatan, dapat dilakukan dengan menetapkan jarak pengukuran dan menghitung waktu tempuh pengiriman data. Dalam penghitungan waktu tempuh, timer pada mikrokontroler dihidupkan dan mencatat waktu terkini selanjutnya timer juga mencatat waktu ketika data kembali. Metoda pengukuran seperti ini biasa disebut ping time. Rumus kecepatan dapat dimodifikasi seperti :

$$
\begin{aligned}
& v=\frac{s}{t} \\
& \text { ping } t=\frac{t_{\text {akhir }}-t_{\text {awal }}}{2} \\
& v=\frac{2 s}{t_{\text {akhir }}-t_{\text {awal }}}
\end{aligned}
$$

Atau dapat dikatakan bahwa nilai kecepatan ditentukan dari penghitungan ping time. Hasil pengukuran ping time dapat dilihat dari gambar 8 .

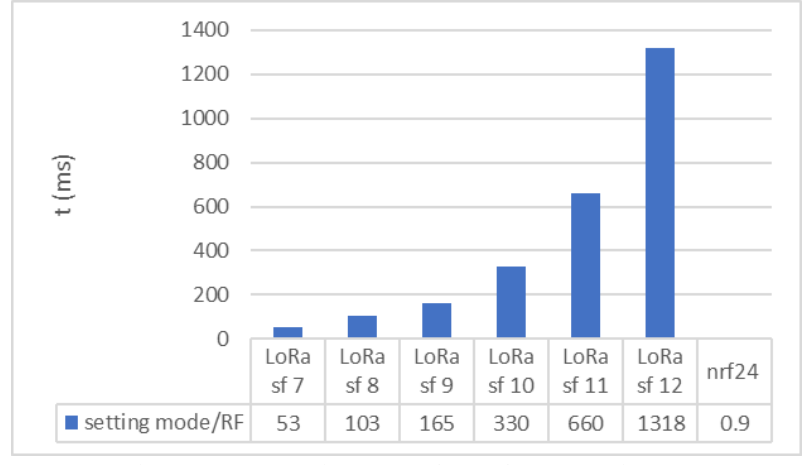

Gambar 8 Pengukuran ping time node JSN

Pada gambar 8 terlihat ping time terbesar adalah pada node JSN LoRa sf 12 yaitu $1318 \mathrm{~ms}$ dan paling kecil adalah node JSN nRF24 $1 \mathrm{~km}$ yaitu $0,9 \mathrm{~ms}$. Jika nilai-nilai ini dimasukan dalam rumus kecepatan transmisi data, kecepatan masing-masing node JSN dapat dilihat dari tabel 1.

Tabel 1 node JSN dan masing-masing kecepatan

\begin{tabular}{lrrr}
\hline Perhitungan kecepatan & $\mathrm{S}(\mathrm{m})$ & $\mathrm{T}(\mathrm{ms})$ & $\mathrm{V}(\mathrm{m} / \mathrm{s})$ \\
\hline Node JSN LoRa sf7 & 400 & 53 & 15094,34 \\
\hline Node JSN LoRa sf8 & 400 & 103 & 7766,99 \\
\hline Node JSN LoRa sf9 & 400 & 165 & 4848,48 \\
\hline Node JSN LoRa sf10 & 400 & 330 & 2424,24 \\
\hline Node JSN LoRa sf11 & 400 & 660 & 1212,12 \\
\hline Node JSN LoRa sf12 & 400 & 1318 & 606,98 \\
\hline Node JSN nRF24 1 km & 400 & 0,9 & 888888,9 \\
\hline
\end{tabular}

Dari tabel 1 terlihat bahwa node JSN nRF24 $1 \mathrm{~km}$ memiliki kecepatan paling tinggi dibandingkan lainnya yaitu $888888,89 \mathrm{~m} / \mathrm{s}$ atau dibulatkan $8,9 \times 10^{5} \mathrm{~m} / \mathrm{s}$. Sedangkan kecepatan paling rendah dimiliki oleh node JSN LoRa sf 12 yaitu $606,98 \mathrm{~m} / \mathrm{s}$ atau dibulatkan $6 \times 10^{2} \mathrm{~m} / \mathrm{s}$.

4. Ketahanan pengiriman data pada situasi non line of sight

Hambatan komunikasi pada JSN berupa noise dan halangan merupakan hal yang tidak dapat dihindarkan ketika node mengirimkan data. Pada bagian ini dilakukan pengukuran persentase pdr dalam pengiriman data ketika node-node terhalang. Pengukuran ini melibatkan beberapa titik pengamatan node yang satu sama lain tidak dapat terlihat secara pandangan atau biasa disebut non-line of sight. Ada 3 titik pengamatan seperti yang terlihat pada gambar 9. 


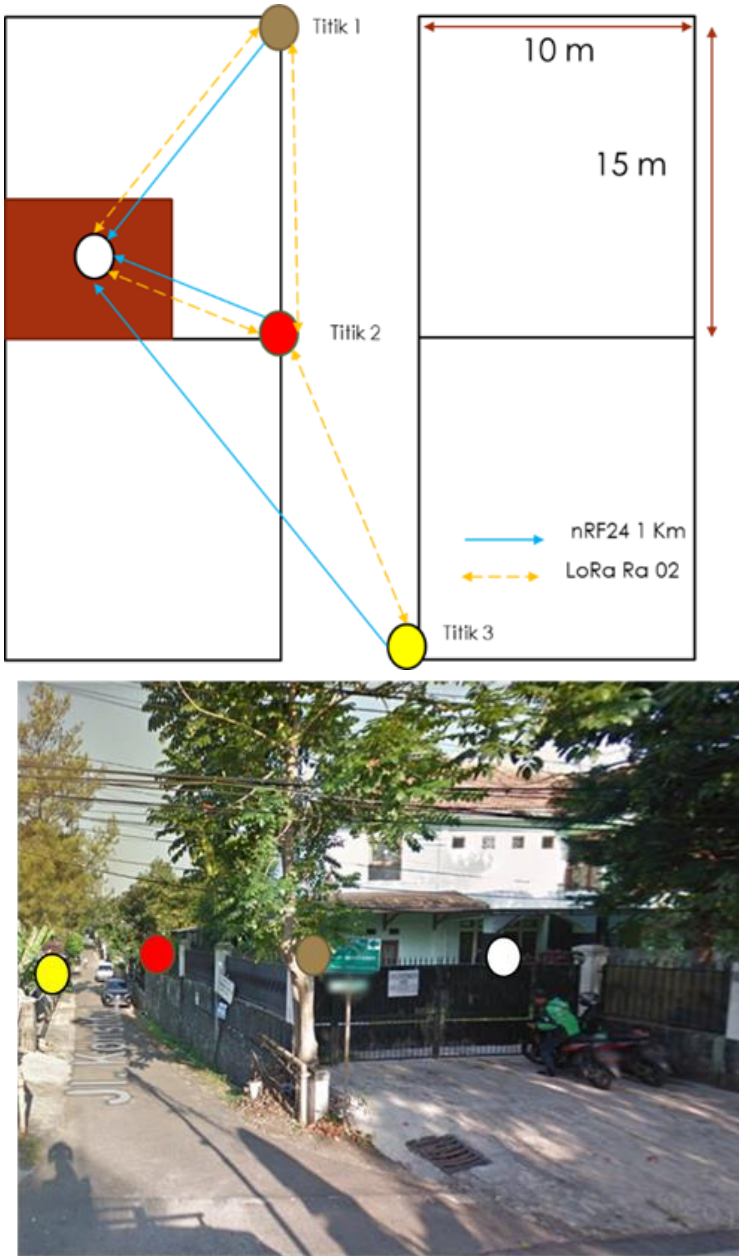

Gambar 9 Titik-titik pengamatan node JSN: (atas) garis komunikasi dan (bawah) keadaan sebenarnya.

Pengukuran persentase pdr dilakukan dengan cara mengirimkan data secara berulang untuk setiap titik sebanyak 100 pengulangan. Kemudian dilakukan pengihitungan persentase pdr berdasarkan banyaknya data yang kembali. Titik pengiriman data berada di dalam rumah (titik putih). Hasil pengukuran pdr dapat dilihat pada gambar 10.

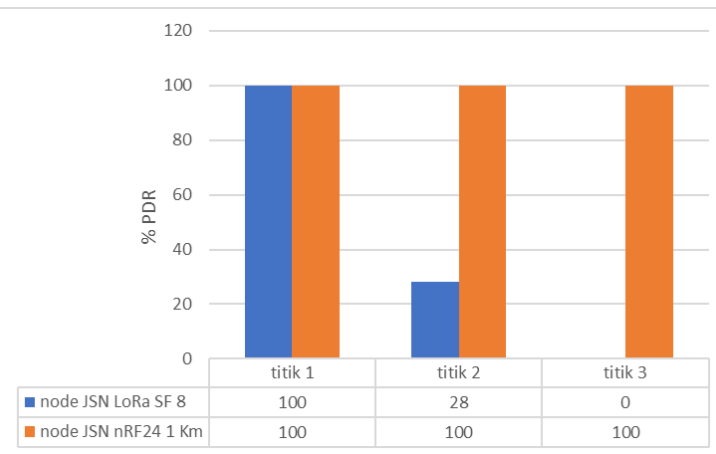

Gambar 10 Grafik pengukuran pdr di 3 titik pengamatan
Pada gambar 10 terlihat grafik pengukuran pdr tiap titik pengamatan. Pada titik pertama, baik node LoRa maupun nRF24 samasama memiliki persentase pdr sebesar $100 \%$. Ketika dilakukan pengiriman data ke titik 3, node LoRa mengalami kegagalan komunikasi dilihat dari tidak adanya data yang kembali ke node pengirim atau $0 \% \mathrm{pdr}$, namun node nRF24 $1 \mathrm{~km}$ masih berkomunikasi dengan baik ditandai dengan nilai persentase pdr sebesar 100 $\%$. Dari pengukuran ini disimpulkan bahwa node JSN nRF24 $1 \mathrm{~km}$ memiliki ketahanan terhadap halangan yang sangat baik dibandingkan node JSN LoRa.

\section{HASIL DAN PEMBAHASAN}

Berdasarkan pengukuran pdr, konsumsi daya dan kecepatan transmisi data oleh LoRa yang telah dilakukan dapat disimpulkan bahwa sf 12 memiliki jangkauan paling jauh, memiliki kecepatan pengiriman paling lama sehingga membutuhkan konsumsi daya lebih banyak dibandingkan sf yang lebih rendah. Hal ini sesuai dengan teori modulasi spektrum LoRa. Modulasi spektrum LoRa dilakukan dengan merepresentasikan setiap bit informasi muatan dengan beberapa kicauan informasi(Wixted et al., 2017). Laju pengiriman informasi sebaran disebut sebagai laju simbol, rasio antara laju simbol nominal dan laju kicauan adalah faktor penyebaran (sf) dan mewakili jumlah simbol yang dikirim per bit informasi. Sf yang lebih rendah berarti lebih banyak kicauan yang dikirim per detik, sehingga penkodeaan data dapat dilakukan lebih banyak per detiknya. Sf yang lebih tinggi berarti lebih sedikit kicauan per detik, sehingga lebih sedikit data untuk dikodekan per detik. Sf yang lebih tinggi membutuhkan waktu transmisi yang lebih lama yang disebut airtime. Lebih banyak airtime berarti modem hidup dan bekerja lebih lama dan mengkonsumsi lebih banyak energi. Manfaat dari sf tinggi adalah bahwa waktu siaran yang lebih lama memberi penerima lebih banyak kesempatan untuk mengambil sampel kekuatan sinyal yang menghasilkan sensitivitas yang lebih baik. Sensitivitas yang lebih baik berarti anda dapat menerima sinyal lebih jauh, sehingga anda mendapatkan jangkauan yang lebih baik (Augustin, et al., 2016).

Berbeda dengan LoRa, nRF24 $1 \mathrm{~km}$ memiliki kecepatan pengiriman paling tinggi ini. Ini sesuai dengan teori modulasi pada nRF24 $1 \mathrm{~km}$ yang modulasi gfsk yang memiliki 
Studi dan Evaluasi Kinerja LoRa Transmitter dan Long Range Radio Frekuensi (RF)

tranfer rate hingga 2 mbps. Dengan nilai tranfer rate yang lebih tinggi membuat nRF24 $1 \mathrm{~km}$ tidak membutuhkan waktu yang lama mengirimkan data. Keuntungannya adalah konsumsi daya menjadi kecil. Ini terbukti pada grafik pada gambar 7. Selain itu, nRF24 $1 \mathrm{~km}$ memiliki ketahanan terhadap halangan yang baik dibandingkan LoRa. Hal ini terjadi karena pada chip nRF24 $1 \mathrm{~km}$ memiliki low-noise amplifier. Fungsi lna adalah untuk mengambil sinyal yang sangat lemah dan tidak pasti dari antena, biasanya pada urutan mikrovolt atau di bawah -100 dbm, dan memperkuatnya ke tingkat yang lebih berguna, biasanya sekitar satu setengah hingga satu volt (gambar 1). Untuk membantu menempatkan ini dalam perspektif, dalam sistem $50 \omega, 10 \mu \mathrm{v}$ adalah -87 dbm dan $100 \mu$ v sama dengan $-67 \mathrm{dbm}$. untuk lna, parameter utamanya adalah noise figure (nf), gain, dan linearitas. Kebisingan disebabkan oleh sumber panas dan lainnya, dengan angka kebisingan tipikal dalam kisaran 0,5 hingga $1,5 \mathrm{db}$. Penguatan biasanya antara 10 dan $20 \mathrm{db}$ untuk satu tahap

\section{KESIMPULAN DAN SARAN}

Studi dan evaluasi kinerja LoRa ra 02 dan nRF24 telah dilakukan dengan baik. Dari beberapa pengukuran yang dilakukan menunjukkan LoRa memiliki jangkauan pengiriman yang lebih jauh yaitu 1,6 km. Ini membuktikan kemampuan modulasi LoRa yang dapat meningkatkan jangkauan tanpa panambahan pengunat daya. NRF24 $1 \mathrm{~km}$ memiliki kecepatan transmisi data yang lebih baik dari LoRa yaitu $600 \mathrm{~ms} /$ paket data. Selain itu, nRF24 juga memiliki ketahanan terhadap halangan non line of sight pada saat pengiriman dibuktikan dengan nilai persetase pdr sebesar 100\%. Ini menunjukkan nRF24 cocok untuk pengiriman data jarak jauh yang memiliki kemungkinan halangan lebih besar dibandingkan LoRa.

\section{DAFTAR PUSTAKA}

Augustin, A., Yi, J., Clausen, T., \& Townsley, W. (2016). A Study of LoRa: Long Range $\&$ Low Power Networks for the Internet of Things. https://doi.org/10.3390/s16091466

Bor, M., Vidler, J., \& Roedig, U. (2016). LoRa for the Internet of Things. International Conference on Embedded Wireless System and Networks2, 361-366. https://doi.org/10.1109/MC.2017.158
Kaleem, Z., Yoon, T. M., \& Lee, C. (2016). Energy Efficient Outdoor Light Monitoring and Control Architecture Using Embedded System. IEE Embedded System Letters, 8(1), 212-215.

Li, L., Hu, X., Chen, K., \& He, K. (2011). The applications of WiFi-based Wireless Sensor Network in Internet of Things and Smart Grid. Proceedings of the 2011 6th IEEE Conference on Industrial Electronics and Applications, ICIEA 2011. https://doi.org/10.1109/ICIEA.2011.5975 693

Muhendra, R., \& Arzi, Y. H. (2017). Development of street lights controller using wifi mesh network. 2017 International Conference on Smart Cities, Automation \& Intelligent Computing Systems (ICON-SONICS), 105-109. https://doi.org/10.1109/ICONSONICS.2017.8267830

Muhendra, R., Husein, Budiman, M., \& Khairurrijal. (2016). Development of digital water meter infrastructure using wireless sensor networks. AIP Conference Proceedings, 1746, 1-7. https://doi.org/10.1063/1.4953950

Petäjäjärvi, J., Mikhaylov, K., Pettissalo, M., Janhunen, J., \& Iinatti, J. (2017). Performance of a low-power wide-area network based on lora technology: Doppler robustness, scalability, and coverage. International Journal of Distributed Sensor Networks. https://doi.org/10.1177/15501477176994 12

Rashed Mohassel, R., Fung, A., Mohammadi, F., \& Raahemifar, K. (2014). A survey on Advanced Metering Infrastructure. In International Journal of Electrical Power and Energy Systems. https://doi.org/10.1016/j.ijepes.2014.06.0 25

Shailandra, K. (2012). An overview of Technical aspect for WiFi Networks Technology. International Journal of Electronics and Computer Science Engineering.

Vullers, R., Schaijk, R., Visser, H., Penders, J., \& Hoof, C. (2010). Energy harvesting for autonomous wireless sensor networks. IEEE Solid-State Circuits Magazine. https://doi.org/10.1109/MSSC.2010.9366 
Rifki Muhendra, Naufal Ismail Kreshnaviyanto, Aisyah Amin

Submitted: 30/10/2020; Revised: 12/01/2021; Accepted: 13/03/2021; Published: 30/04/2021

67

Wixted, A. J., Kinnaird, P., Larijani, H., Tait, A., Ahmadinia, A., \& Strachan, N. (2016). Evalution of LoRa and LoRaWAN for Wireless Sensor Network. IEEE, O(June), 5-7.

Wixted, A. J., Kinnaird, P., Larijani, H., Tait, A., Ahmadinia, A., \& Strachan, N. (2017).
Evaluation of LoRa and LoRaWAN for wireless sensor networks. Proceedings of IEEE Sensors. https://doi.org/10.1109/ICSENS.2016.78 08712 